Military Technical College, Kobry El-Kobbah, Cairo, Egypt

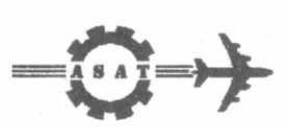

$9^{\text {th }}$ International Conference

On Aerospace Sciences \&

Aviation Technology

\title{
DESIGN OF THE HELICOPTER-MOUNTED FLIR SYSTEM WITH FOUR-AXIS GIMBAL STABILIZATION
}

\author{
Haeng Bok Lee*
}

\begin{abstract}
The Helicopter Forward Looking InfraRed (HFLIR) system is a lightweight, multipurpose, thermal imaging sensor for pilotage/navigation, surveillance, searchand-rescue, automatic tracking and targeting. It is a four-axis gimbal assembly, gyrostabilized in both azimuth and elevation. Design conditions for the gimbal assembly include operation and non-operational inertial, thermal, and dynamic loads. Design goals centered on augmenting stiffness and reduce weight to achieve relatively high modal performance, and also a study was performed to select key components in the gimbal hardware that are essential to meeting the performance objectives. A finite element model was used to maximize the fundamental frequency and select the best configuration the inner gimbal assembly of the turret FLIR unit (TFU). As a result, the fundamental frequency of the gimbal assembly met the design and performance requirements and was selected to meeting the performance objectives include torque motors, bearings, seals and position sensors.
\end{abstract}

\section{KEYWORDS}

Turret FLIR Unit, Inner Gimbal Assembly, natural frequency, vibration test

\section{INTRODUCTION}

Electro-optical tracking and pointing systems require precision stabilization of the line of sight in order to maintain the imaging sensor resolution and to precision point. The design of these systems requires an integrated optical sensor sensitivity and resolution, field of regard, slew rates and pointing, mechanical, electrical design effort to achieve the required line of sight stability, accuracy. The Helicopter Forward Looking InfraRed (HFLIR) is a helicopter-borne tracking system. Its goals are to perform search-and-rescue target detection and are matched to the night flying requirements for helicopter operations. The HFLIR system comprises the

* Technology Research Center, Agency for Defense Development, P.O. Box 35-5, Yuseung, Daejon, 305-600, Korea. 
following four units, that is Turret FLIR Unit (TFU), System Electronics Unit (SEU), Multifunction Dispiay Unit (MFDU) and Multifunction Control Unit (MFCU). The TFU employs a four-axis gimbal system, with an azimuth and elevation as the inner gimbal and the outer gimbal. The four-axis gimbal system are outer coarse gimbals, coarse elevation (CEL) and coarse azimuth (CAZ) motion, and inner fine gimbals, fine elevation (FEL) and fine azimuth (FAZ) motion. The outer two-axis gimbal consists of a coarse azimuth drive assembly and a coarse elevation yoke that supports and drives the inner two-axis gimbal assembly. The yoke is comprised of the structure of the azimuth bearing/motor housing and a pair of clevises mounted to the ends of the beam structure. The coarse azimuth drive is supported by a cylindrical inner housing and utilizes a pair of angular contact ball bearings to support the outer housing and coarse elevation yoke. The elevation drive consists of left and right support clevises, bearing assembles, and the elevation drive torque motor with its mounting. The inner two-axis gimbal consists of a fine azimuth drive assemblies and a fine elevation drive assemblies, and each drive assembly is mounted at right, left, upper and lower center positions around an inner gimbal frame. In the inner gimbal, directly coupled DC torque motors drive the gimbal about the azimuth and the elevation axis These torque motors are able to provide a gimbal acceleration of $90 \% \mathrm{sec}^{2}$ at airspeeds in excess of $300 \mathrm{~km} / \mathrm{hr}$, and a slew rate of $60 \% \mathrm{sec}$. The structural parts of the turret are aluminum castings except for the bearing attachment areas. The TFU contains the electronic, optical, and mechanical elements required for thermal imaging and for directing and stabilization the sensor line of sight. The stabilized four-axis gimbal provides isolation from sources of image motion and jitter, allowing for maximum performance of the imaging sensor. The TFU consists of the thermal imager assembly (FLIR Sensor), which collects IR scene radiation and electro-optically converts the scene to a raw video signal, electro-mechanical drive elements of the gimbaled turret that point and stabilize the sensor's LOS, a hermetically sealed enclosure that shields the sensor from the environments. The FLIR Sensor is mounted on an optical bench of an inner gimbal assembly for TFU. The gimbal sybsystem provides movement and stabilization of the TFU; its major components are the torque motors, bearings, position sensors, seals, gyroscope and supporting structures. The azimuth travel of the LOS provided by the turret is continuous 360 degrees, and the elevation travel is 45 degree down and 120 degree up, providing complete hemispheric coverage of the area surrounding the vehicle.

\section{SYSTEM REQUIREMENTS}

The system requirements used to provide guidance for designing the gimbal mechanical, electrical components and supporting structure. The basic requirements of the HFLIR are:

- The HFLIR shall be capabie of tracking a target with a line of sight rate of $60 \% \mathrm{sec}$ and an acceleration of $90 \% \mathrm{sec}^{2}$

- Field of Regard $-42^{\circ}$ to $120^{\circ}$ of elevation angle with full azimuth coverage $360^{\circ}$.

- The HFLIR TFU weight shall be less than $30 \mathrm{~kg}$.

- The structure of the HFLIR TFU must have sufficient stiffness so that the first structural mode is $100 \mathrm{Hertz}$, minimum 


\section{MAJOR COMPONENTS SELCTION}

Key components in the TFU hardware that are essential to meeting the performance objectives include a torque motors with low hysteresis for providing torque about the azimuth and the elevation axis, a bearing for supporting the gimbal assembly, an accurate lightweight capacitive pickoff device for angular measurement about the azimuth and the elevation axis of the inner/outer gimbal, and the selection of seal parts to insure waterproofing.

\subsection{Torque Motor Selection}

The torque motors are a conventional brush type design using samarium magnets for maximum performance and small size. The outer gimbal has two torque motors for driving azimuth and elevation motion, also the inner gimbal do. The torque motor performance data are summarized in Table 1.

Table 1. Torque Motor Performance Data

\begin{tabular}{|l|l|l|}
\hline & FEL/FAZ/CEL & CAZ \\
\hline Peak Torque, $T_{\mathrm{P}}[\mathrm{lb}-\mathrm{ft}]$ & 140 & 700 \\
\hline Power at $T_{\mathrm{p}}, \mathrm{P}_{\mathrm{P}}[\mathrm{W}]$ & 83 & 102 \\
\hline No Load Speed, $\varpi_{\mathrm{NL}}[\mathrm{rad} / \mathrm{s}]$ & 80 & 19 \\
\hline Elect. Time Constant, $\tau_{\mathrm{e}}[\mathrm{ms}]$ & 0.0002 & 0.0004 \\
\hline Voltage at $\mathrm{T}_{\mathrm{p}}, \mathrm{V}_{\mathrm{P}}[\mathrm{V}]$ & 22.6 & 20.9 \\
\hline Current at $\mathrm{T}_{\mathrm{P}}, \mathrm{I}_{\mathrm{p}}[\mathrm{A}]$ & 3.71 & 5.34 \\
\hline Resistance, $\mathrm{R}_{[}[\Omega]$ & 6.1 & 3.9 \\
\hline Torque Sensitivity, $\mathrm{K}_{\mathrm{T}}[\mathrm{lb}-\mathrm{ft} / \mathrm{A}]$ & 37.7 & 131 \\
\hline Back E.M.F., $\mathrm{K}_{\mathrm{B}}[\mathrm{V} / \mathrm{rad} / \mathrm{s}]$ & 0.266 & 0.92 \\
\hline
\end{tabular}

\subsection{Bearing}

An important feature that has been incorporated into the gimbal design is the use of custom bearings for supporting the gimbal assembly. The bearings are selfaligning, exhibit low friction and provide high load capability. The bearing data are summarized in Table 2.

Table 2. Bearing Data

\begin{tabular}{|c|c|c|c|c|}
\hline & \multicolumn{2}{|c|}{ Load Capabilities } & \multirow{2}{*}{$\begin{array}{l}\text { Friction } \\
\text { Torque }\end{array}$} & \multirow{2}{*}{ Preload } \\
\hline & Radial & Thrust & & \\
\hline FEL Right Bearing & $140 \mathrm{lb}$ & $360 \mathrm{lb}$ & $0.03 \mathrm{Nm}$ & $15-20 \mathrm{lb}$ \\
\hline FEL Left Bearing & $140 \mathrm{lb}$ & $360 \mathrm{lb}$ & $0.03 \mathrm{Nm}$ & $15-20 \mathrm{lb}$ \\
\hline FAZ Upper Bearing & $140 \mathrm{lb}$ & $360 \mathrm{lb}$ & $0.03 \mathrm{Nm}$ & $15-20 \mathrm{lb}$ \\
\hline FAZ Lower Bearing & $310 \mathrm{lb}$ & $780 \mathrm{lb}$ & $0.03 \mathrm{Nm}$ & $15-20 \mathrm{lb}$ \\
\hline $\begin{array}{ll}\text { CEL } & \text { Right/Left } \\
\text { Bearing } & \end{array}$ & $726 \mathrm{lb}$ & $1830 \mathrm{lb}$ & $0.035 \mathrm{Nm}$ & - \\
\hline CAZ Bearing & 910lb & $2640 \mathrm{lb}$ & $0.3 \mathrm{Nm}$ & $100 \mathrm{lb}$ \\
\hline
\end{tabular}

\subsection{Seal}

An immersion test method of the TFU is that three times immersion for lowermost point of the TFU is $1 \pm 0.1 \mathrm{~m}$ below the surface of the water, 30 minutes immersion period. The seal data are shown in Table 3. 
Table 3. Seal Data

\begin{tabular}{|l|l|l|l|}
\hline & Dimension & Pressure & Friction \\
\hline CEL Seal & $\Phi 12^{\prime \prime}$ & $20 \mathrm{kpa}$ & $<0.04 \mathrm{Nm}$ \\
\hline CAZ Seal & $\Phi 3.1^{\prime \prime}$ & $20 \mathrm{kpa}$ & $<0.3 \mathrm{Nm}$ \\
\hline
\end{tabular}

\subsection{Position Sensor}

A proven aerospace qualified coarse resolver was selected to measure angular motion about the azimuth and elevation axis. These units have a high resolution, $8: 1$ speed, fine winding, with accuracy of 20 arcseconds. These transducers were selected based on its weight and size. It resolves over the angular range of 360 degrees of azimuth and elevation axis.

\subsection{Gyro}

The selected gyro in the turret belongs to the Dynamically Tuned Gyro. The DTG is a two-axis, spinning mass, inertial rate sensor. The use of a single two-axis DTG for line of sight stabilization is considered a smail volume and low cost solution when compared with the once common pair of single-axis rate integrating gyros.

\subsection{Slip Ring}

A slip ring assembly was incorporated in coarse azimuth so that continuous rotation could be maintained. Drive mechanism wires and position sensor wires were required to go through the slip ring assembly.

\section{STRUCTURAL DESIGN REQUIREMENTS}

Natural frequencies must be tailored to avoid harmful coupling of modes and resonant amplifications. For a minimum frequency of the TFU structure, greater than $100 \mathrm{~Hz}$ for major mode is desired. Further design requirements were categorized based on anticipated operational and non-operational flight environments. The TFU was designed to withstand a non-operational shock input of $15 \mathrm{~g}$ acting for $11 \mathrm{msec}$. The non-operational thermal environment ranged from $35^{\circ} \mathrm{C}$ to $+50^{\circ} \mathrm{C}$. Table 4 . Summarizes of the critical design requirements that were addressed.

Table 4. Structural Design Requirements

\begin{tabular}{|l|l|}
\hline \multicolumn{2}{|c}{ Table 4. Structural Design Requirements } \\
\hline Shock & MIL-STD-810E \\
\hline Temperature & $15 \mathrm{~g}, 11 \mathrm{msec}$, Half-sine pulse \\
\hline The first significant structural mode & $-35^{\circ} \mathrm{C}$ to $+50^{\circ} \mathrm{C}$ \\
\hline
\end{tabular}

4.1 Mass and Center of Gravity Requirement

The total TFU mass requirement is less than $30 \mathrm{~kg}$, and the vertical center of gravity requirements is no greater than $150 \mathrm{~mm}$ above the center interface, and within a $2 \mathrm{~mm}$ radius of the centerline for center.

\subsection{Frequency Requirement}

The HFLIR TFU must have sufficient stiffness so that the first structural mode is $100 \mathrm{Hertz}$, minimum. 


\section{STRUCTUAL ANALYSIS}

The TFU structure was designed to meet the structural, in particular, the structural design requirements shown in Table4. In order to satisfy these requirements and to assure that adequate margins of safety exist from a strength and stability standpoint, a detailed finite element model of the structural assembly was developed and subsequently analyzed using MSC/NASTRAN. For a minimum frequency of the TFU structure, greater than $100 \mathrm{~Hz}$ for major mode is desired. The requirement was very difficult to satisfy due to the weight of the equipment components and the unique sensor support geometry in a volume limited by the interior dimensions of the TFU. In order to meet this requirement, the optimization routine was then employed to maximize the fundamental frequency of the gimbal assembly. The TFU inner gimbal assembly is shown in Figure 1. During modeling of the TFU, small part as will be modeled as lumped masses. Effects of electronic boxes and other small components will be represented by discrete masses distributed on their support structures. The total mass of the model will be estimated including mass margins reserved for design uncertainties. The design variables were resized and several stiffeners were added to boost the natural frequency. Structural modifications were implemented after an initial analysis to stiffen the frame. The modal analysis of the TFU gimbal structure was completed and the first 4 frequencies were calculated. The frame was found to be extremely stiff with a first fundamental frequency of $125 \mathrm{~Hz}$ and a mass of $29 \mathrm{~kg}$. A summary of the first four predicted fundamental frequencies is presented in Table 5.

Table 5. TFU inner gimbal fundamental frequencies

\begin{tabular}{|l|l|}
\hline Fundamental & Frequencies \\
\hline F1 & $125 \mathrm{~Hz}$ \\
\hline F2 & $127 \mathrm{~Hz}$ \\
\hline F3 & $139 \mathrm{~Hz}$ \\
\hline F4 & $176 \mathrm{~Hz}$ \\
\hline
\end{tabular}

Modal shape plots for the first four fundamental frequencies are presented in Figures 2 through 5.

\section{VIBRATION TESTING}

Vibration testing with the TFU was useful in validating the initial design, because design weaknesses could be detected and changed early in the design process. The modal frequency analysis requirement of $100 \mathrm{~Hz}$ was a critical parameter and also difficult to achieve. To verify the accuracy of the analytical predictions, a vibration test was performed. Typically, a white noise $0.5 \mathrm{grms}$ random input from $5-500 \mathrm{~Hz}$ was input to the three axes of the TFU. Gyro mounted on the frame was used to record the angular rates about the elevation and azimuthally axes during the test. Accelerometers, mounted to the gimbal assembly, helped determine the structural frequencies and mode shapes. Figure 6 shows the TFU ready for a pure sinus test. The measured response spectrums of the TFU testing results were shown in Figures 7 through 12. This testing confirmed the confidence in the modeling techniques, modeling assumptions, and material properties used in the analyses. 


\section{SUMMARY}

A study was performed to select key components include the toque motors, bearings, position sensors and seals. The primary resunance ar:c mode shapes of a TFU inner gimbal frame were evaluated with a MSC/NASTRAN finite element model solution and test results were obtained from $0.5 \mathrm{~g}$ sine sweeps. A design goal a first mode resonant frequency of a $100 \mathrm{~Hz}$ was achieved and the design primary driver of a weight under $30 \mathrm{~kg}$ was realized. Results showed excellent correlation between analysis and data on the first four modes.

\section{REFERENCES}

1. K.B. Doyle, V.J. Cerrati, S.E. Forman and J.A. Sultana, Optimal structural design of the Airborne Infrared Imager, SPIE Optomechanical and Precision Instrument Design, Vol.2542, pp11-15, 1995

2. P.R.Yoder, Jr., Opto-mechanical Systems Design, Marcel-Dekker, New York, 1986

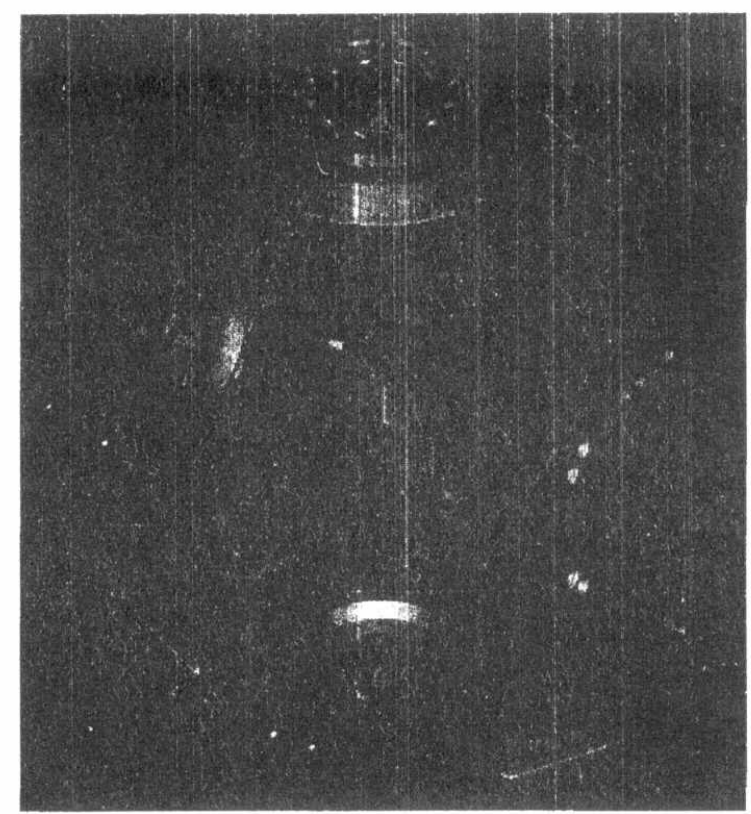

Figure 1. TFU Inner Gimbal Assembly 


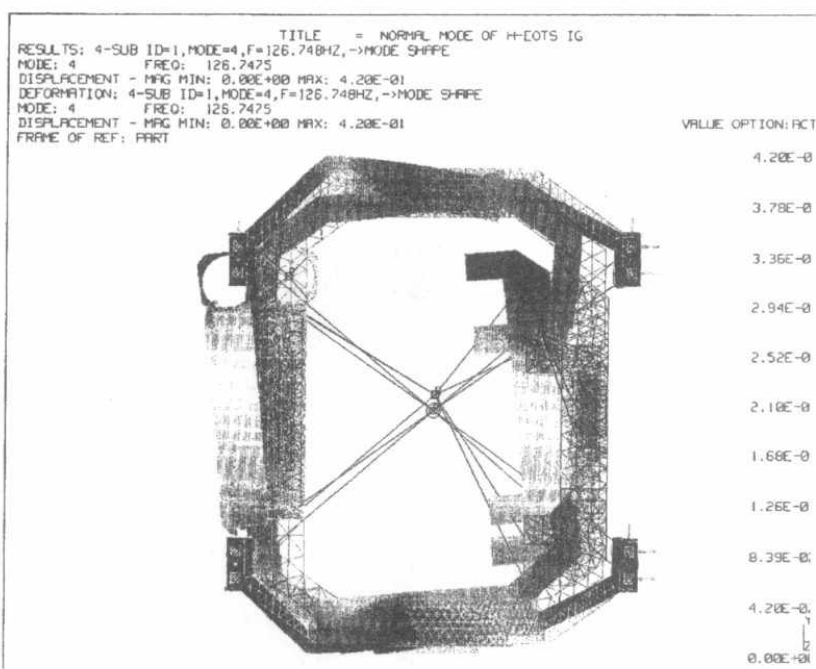

Figure 2. TFU Inner Gimbal Frame $1^{\text {st }}$ mode $(125 \mathrm{~Hz})$

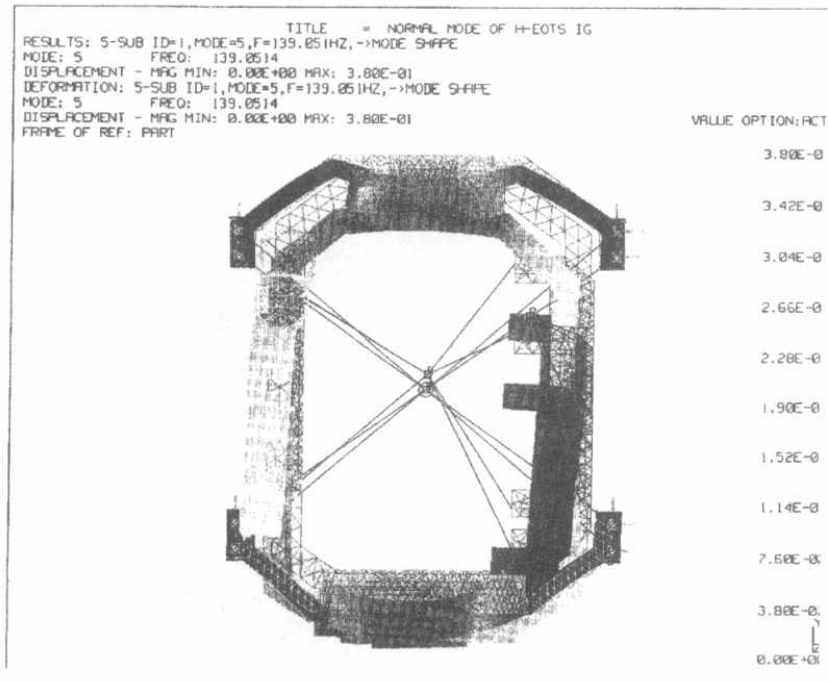

Figure 3. TFU Inner Gimbal Frame $2^{\text {nd }}$ model $(127 \mathrm{~Hz})$ 


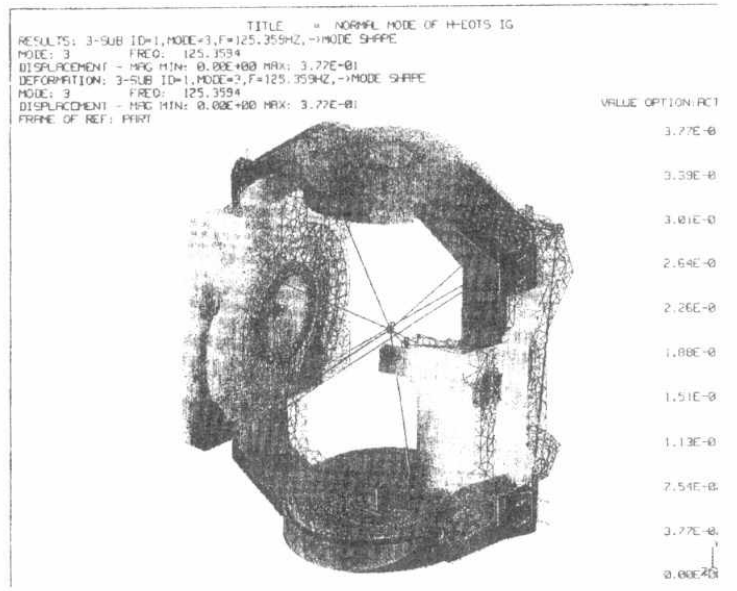

Figure 4. TFU Inner Gimbal Frame $3^{\text {th }}$ mode $(139 \mathrm{~Hz})$

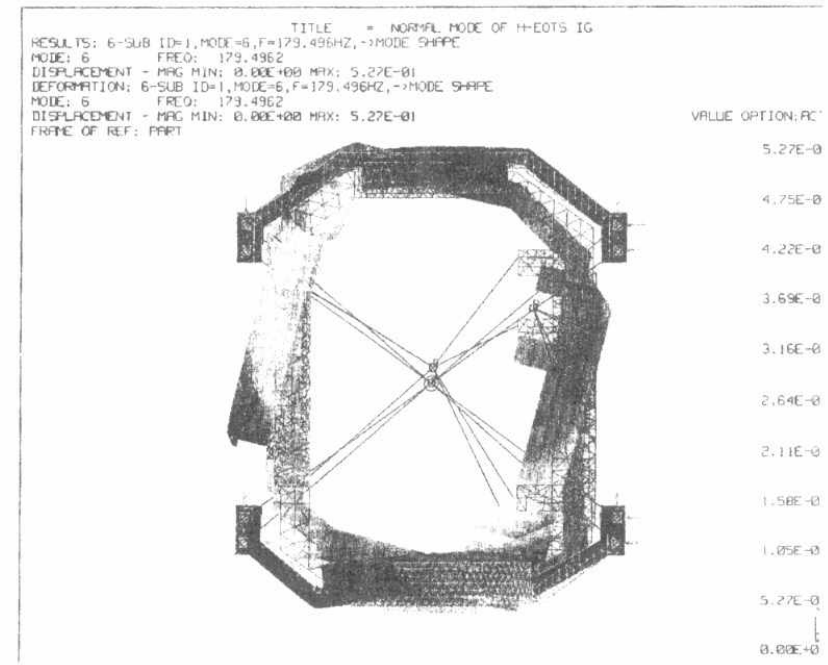

Figure 5. TFU Inner Gimbal Frame $4^{\text {th }}$ mode $(176 \mathrm{~Hz})$ 


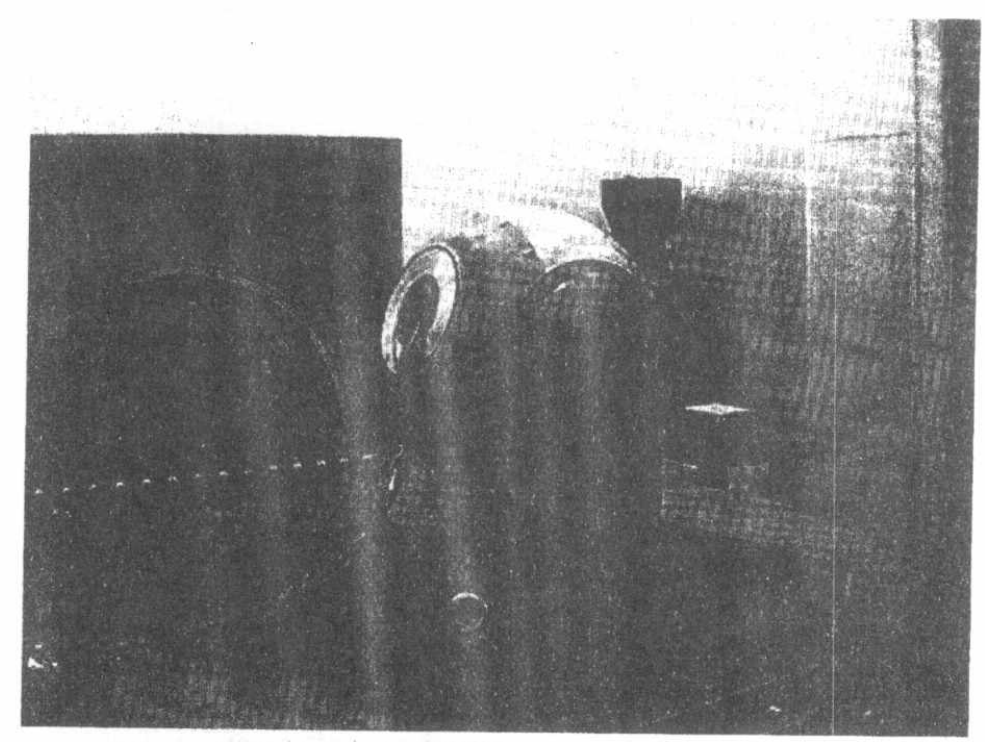

Figure 6. Photograph of TFU Vibration Test Set-Up

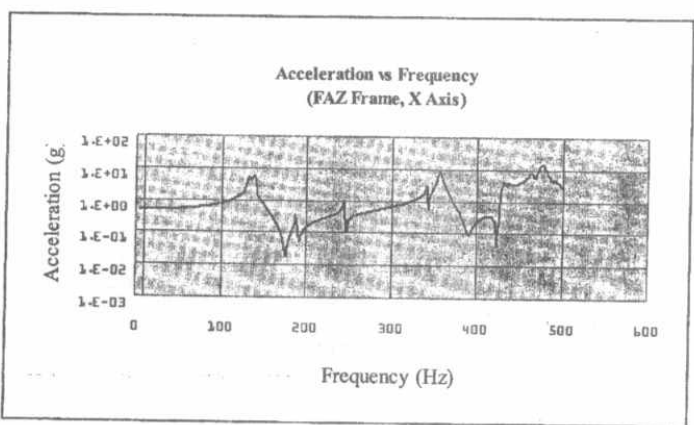

Figure 7. Test Result of FAZ Frame, X-Axis Direction 


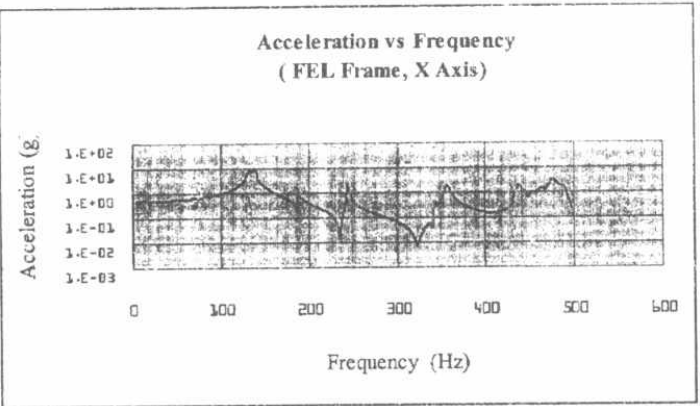

Figure 8. Test Result of FEL Frame, X-Axis Direction

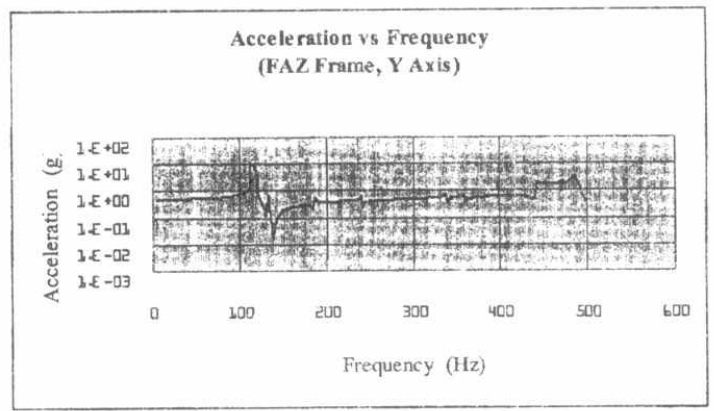

Figure 9. Test Result of FAZ Frame, Y-Axis Direction

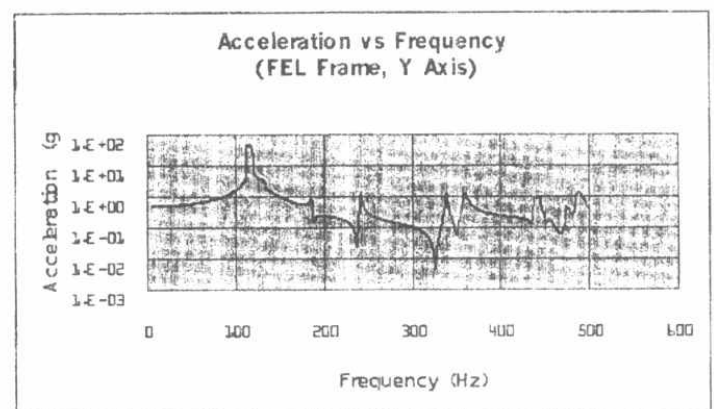

Figure 10. Test Result of FEL. Frame, Y-Axis Direction 


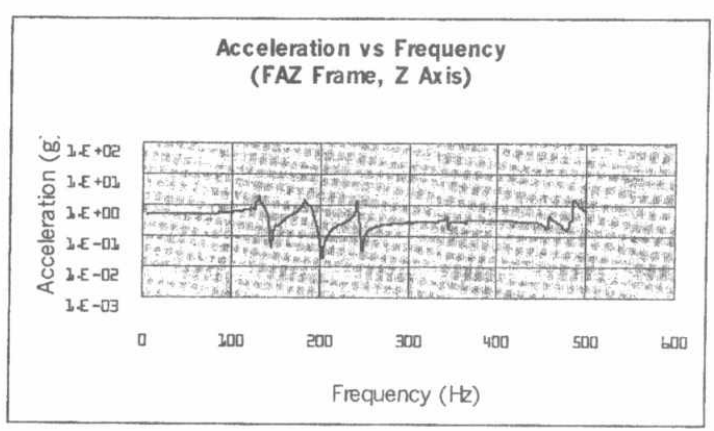

Figure 11. Test Result of FAZ Frame, Z-Axis Direction

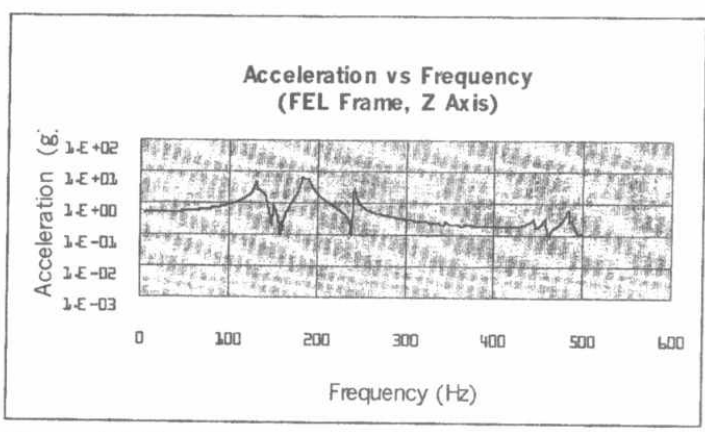

Figure 12. Test Result of FEL Frame, Z-Axis Direction 